\title{
Temperature and precipitation scenarios for Norway: comparison of results from dynamical and empirical downscaling
}

\author{
I. Hanssen-Bauer*, E. J. Førland, J. E. Haugen, O. E. Tveito \\ Norwegian Meteorological Institute, PO Box 43, Blindern, 0313 Oslo, Norway
}

\begin{abstract}
A scenario from the coupled atmosphere-ocean climate model ECHAM4/OPYC3 was downscaled by empirical and dynamical methods to show projected changes in temperature $(T)$ and precipitation $(R)$ in Norway under global warming. In the empirical models, large-scale $T$ was applied as a predictor for $T$. For $R$, both $T$ and sea-level pressure (SLP) were applied as predictors during most of the year, while only SLP was applied during summer. The dynamical model, HIRHAM, is a regional climate model based upon HIRLAM, but with physical parametrisations from ECHAM4/ OPYC3. Both approaches project from 1980-1999 to 2030-2049 an increase in annual mean temperatures of between 1 and $2.5^{\circ} \mathrm{C}$ in various parts of the country. The projected warming is at a minimum along the southern coast, while greater warming is projected inland and in the north. Though the differences between the approaches are not statistically significant, empirical downscaling systematically leads to a larger projected increase in annual mean temperature than dynamical downscaling does. The difference is at a maximum during winter and/or spring at localities exposed to temperature inversions. Empirical downscaling projects larger winter warming in inland valleys than at more freely exposed localities, and thus implies a reduced intensity or frequency of winter inversions. It is argued that less favourable conditions for ground inversions are consistent with the future projection of increased winter wind speeds and reduced snow-cover. For precipitation, both downscaling approaches project a statistically significant increase in the west during autumn, and in the south during winter. The only significant difference between the results is that dynamical downscaling projects increased summer precipitation in the southwest, while the empirically downscaled scenario shows no significant change. For summer precipitation the present empirical models do not include any predictor carrying the 'climate change signal', and thus the results from the dynamical downscaling are probably more realistic concerning summer precipitation.
\end{abstract}

KEY WORDS: Dynamical downscaling - Empirical downscaling - Temperature Precipitation · Norway

\section{INTRODUCTION}

Coupled atmospheric-ocean global general circulation models (AOGCMs) are the most sophisticated tools for modelling global warming. The resolution in the AOGCMs is presently probably sufficient for modelling large-scale features, but in general still too coarse to enable these models to reproduce the climate on a regional or local scale (e.g. Yarnal et al. 2001). In order to produce regional scenarios, downscaling is thus necessary. Regional modelling (dynamical downscaling), statistical methods (empirical downscaling) or combinations of these techniques may be applied for this purpose (e.g. Giorgi et al. 2001). In their review of recent developments within empirical and dynamical downscaling, Yarnal et al. (2001) concluded that both 
methodologies have strengths and weaknesses, but that they both provide a complementary perspective on the climate system. They stressed the importance of continued comparisons to determine why, where and when one methodology outperforms the other.

A few inter-comparisons of results from dynamical and empirical downscaling have been published (Kidson \& Thompson 1998, Murphy 1999, Hellström et al. 2001). Hellström et al. (2001) found that the temporal and spatial variability of precipitation changes in Sweden were higher in the empirical downscaled scenarios than in corresponding dynamical downscaled ones. Murphy (1999) estimated that the overall levels of skill of empirical and dynamical downscaling methods for monthly temperatures were similar over Europe, although Murphy (2000) reported that the empirically downscaled results tended to be less similar to the AOGCM output than the results from dynamical downscaling. Kidson \& Thompson (1998) reported similar skills for empirical and dynamical techniques concerning downscaling of daily and monthly temperature and precipitation, though the empirical models were inferior concerning convective precipitation.

In Norway, both dynamical and empirical techniques have been applied to downscale results from the same AOGCM, enabling a consistent platform for evaluation of strong and weak aspects of each methodology. The downscaling experiments are based upon the

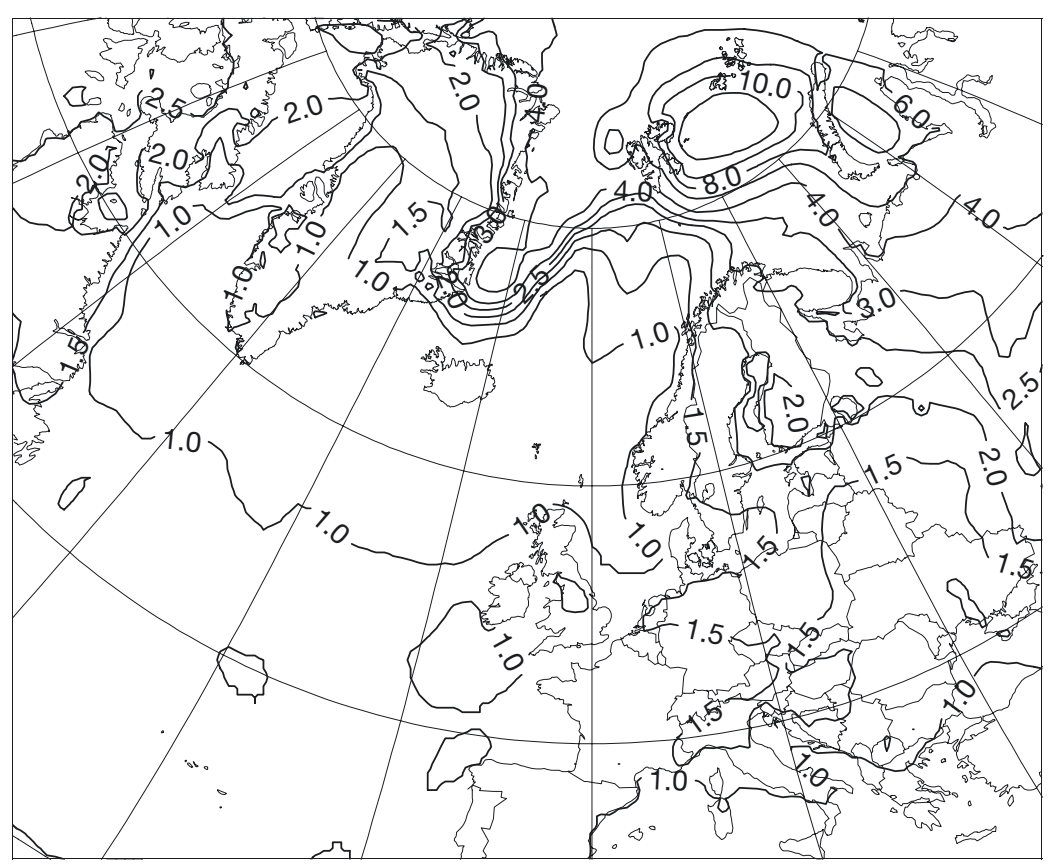

Fig. 1. HIRHAM regional climate model integration area with contours for increased winter temperature at $2 \mathrm{~m}$ from 1980-1999 to 2030-2049 downscaled from the ECHAM4/OPYC3 GSDIO simulation
ECHAM4/OPYC3 'GSDIO' integration (Oberhuber 1993, Roeckner et al. 1996, 1999), a transient integration based upon the IS92a emission scenario, and including greenhouse gases, tropospheric ozone, and direct as well as indirect sulphur aerosol forcing. The GSDIO integration did well in a comparative study where several integrations were compared to observed temperature anomalies during 1946-1996 (Allen et al. 2000).

In the present paper, temperature and precipitation scenarios for Norway resulting from the 2 downscaling approaches are compared. Section 2 shortly describes the dynamical and empirical modelling tools. The results of the comparison are presented in Section 3 and discussed in Section 4.

\section{DOWNSCALING EXPERIMENTS}

\subsection{Dynamical downscaling}

Since AOGCMs only support large-scale and synoptic-scale atmospheric features, regional climate models (RCMs) have been developed over the last few decades for dynamical downscaling of AOGCMs at regional and local scales. The hypothesis behind the use of high-resolution RCMs is that they can provide meaningful small-scale features over a limited area at affordable computational cost compared to highresolution GCM simulations. The HIRHAM RCM used in the present study was run with a $55 \mathrm{~km}$ grid distance nested within the global data, available every $12 \mathrm{~h}$ with a $300 \mathrm{~km}$ grid. The same physical parametrisations are used in the RCM as in the global model, except for tuning to account for the finer grid in HIRHAM. The same 19 model levels were used in the vertical direction. The integration area is shown in Fig. 1.

Successful implementation of an RCM depends on a number of conditions, e.g. nesting strategy, domain size, difference in resolution between the AOGCM and RCM, the physical parametrisations, quality of the driving data and spin-up time. Generally the RCM cannot be expected to improve errors in the AOGCM results on a large scale, but should be able to develop small-scale features, at least due to more realistic surface forcing. As for its global counterpart, it is certainly necessary to realistically simu- 
late present climate, for which analysed and observed data can be used for validation, as a first attempt to trust the output from climate-change experiments. Validations of the ECHAM4/OPYC3 control climate (Christensen et al. 1998, Machenhauer et al. 1998, Hanssen-Bauer \& Førland 2001) show that the largescale temperature fields over Scandinavia are realistic. The sea-level pressure (SLP) fields are biased as the average north-south SLP gradient in the northern North Atlantic is somewhat too weak; however, the SLP anomaly fields are still realistic.

HIRHAM originates from HIRLAM (high-resolution limited-area model), a short-range weather prediction model (Källén 1996). The numerical formulation is a second-order finite-difference scheme, and the timescheme is the Eulerian leap-frog, semi-implicit timescheme with a time step of $4 \mathrm{~min}$. In order to be better suited for long-term climate simulation, the physical parametrisations were adopted from the ECHAM4/ OPYC3 AOGCM (Roeckner et al. 1996), and they are documented by Christensen et al. (1998). The experiments performed with the GSDIO data are reported in Bjørge et al. (2000). The physical parametrisations in HIRHAM include radiation, cumulus convection utilising the mass flux scheme of Tiedke (1989), stratiform clouds, the planetary boundary layer, gravity wave drag, sea-surface and -ice processes, and land processes including surface hydrology. In the land-surface scheme, temperature is calculated as a prognostic variable for 5 soil layers and 1 moisture layer. A simple 1-layer snow model is coupled to the land-surface scheme (DKRZ 1992, Christensen et al. 1996). The albedo of snow (and ice) is parametrised to be temperature dependent near melting (decreasing albedo with increasing temperature). The effect on vegetation on albedo during snow-covered periods is parametrised over fractional forested area, effectively reducing the albedo with increasing forest coverage (Robock 1980).

The HIRHAM simulation from the GSDIO experiment was carried out in 2 time-slices, 1980-1999 and 2030-2049, with lateral boundary conditions for surface pressure, temperature, horizontal-velocity components, specific humidity and liquid cloud water in $12 \mathrm{~h}$ intervals and with sea-surface temperature and sea-ice conditions specified from the global model. Monthly concentrations of various greenhouse gases were tabulated as in the global counterpart according to the IS92a scenario with observed values until 1990 followed by a $1 \%$ yearly increase in $\mathrm{CO}_{2}$.

\subsection{Empirical downscaling}

Empirical downscaling of climate scenarios consists of revealing empirical links between large-scale pat- terns of climate elements (predictors) and local climate (predictands), and applying them to the output from global or regional climate models. Successful downscaling depends on the following conditions: (1) the climate model should reproduce the large-scale predictor fields realistically, (2) the predictors should account for a major part of the variance in the predictands, (3) the links between predictors and predictands should be stationary, and (4) when applied in a changing climate, predictors that 'carry the climate change signal' should be included (Giorgi et al. 2001).

In the present study, monthly mean $2 \mathrm{~m}$ temperature $(T)$ and precipitation $(R)$ at selected localities are the predictands, while $T$ and SLP were used as predictors. Homogenised $T$ and $R$ series from Norwegian stations (source: Norwegian Meteorological Institute; HanssenBauer \& Førland 1994, Nordli 1997), and interpolated gridded monthly $T$ and SLP from the UK Met Office and University of East Anglia (Jones 1987, Jones et al. 1998) were applied for model development and validation. The gridded datasets have a $5^{\circ}$ resolution, and the area $20^{\circ} \mathrm{W}-40^{\circ} \mathrm{E}, 50-85^{\circ} \mathrm{N}$ was applied as the predictor domain for SLP, while just the grid-points over Norway were used for $T$. Model data were interpolated to the same grid. The large-scale SLP anomaly fields and $T$ fields over Norway are realistically reproduced by the ECHAM4/OPYC3, and so are the links between SLP anomalies and temperature anomalies (Hanssen-Bauer \& Førland 2001). Hanssen-Bauer \& Førland (2000) showed that SLP anomalies account for a large part of the observed variability of temperature and precipitation in Norway during the twentieth century. The long-term trends, especially for temperature, were, however, not reproduced satisfactorily. Because of this, and in order to include the climate change signal, $T$ was included as a predictor. For temperature, $T$ was used as the only predictor in the final models as the SLP field gave limited additional information. For precipitation both predictors were included initially. Ideally, air humidity should also be included as a predictor for precipitation; however, finding a high-quality dataset of air humidity covering the twentieth century has been a problem. In the present models, $T$ may be regarded as a proxy for precipitable water in the troposphere and thus to some degree make up for not including air humidity as a predictor. In summer, however, the inclusion of $T$ as a predictor led to unrealistic results. This may be caused partly by a poorer correlation between air temperature and humidity, and partly by a weaker connection between air humidity and precipitation during summer (Wilby \& Wigley 2000). Consequently, in the final models, $T$ was not applied as a predictor for precipitation during the summer months. This is unsatisfactory, as eventual modelled changes in summer precipitation will thus reflect atmospheric circulation changes only. 
Hanssen-Bauer et al. $(2000,2001)$ have described the downscaling methods and results in detail for temperature and precipitation, respectively. A brief summary of the methods is given here. For temperature, a simple scaling procedure was applied. Using a method suggested by Singleton \& Spackman (1984), Norway was divided into 6 temperature regions (Fig. 2a) within which standardised monthly temperature series are similar. Thus, a standardised temperature series from one station in a region is representative for the region. Comparisons with the gridded temperature data set (Jones et al. 1998) showed that also standardised series from grid-points within the respective regions are close to the regions' representative series. Thus the temperature at a $\operatorname{Stn} x$ in region $n$ can be estimated by the temperature at the grid-point $y$ within the same region:

$$
T_{x n}=\left\{\left[T_{y n}-\mu\left(T_{y n}\right)\right] / \sigma\left(T_{y n}\right)\right\} \cdot \sigma\left(T_{x n}\right)+\mu\left(T_{x n}\right)
$$

Here $T_{x n}$ is the local temperature, $T_{y n}$ is the temperature at a nearby grid-point within the same region $n$, $\mu$ is the mean value and $\sigma$ is the standard deviation. When developing the models, 1961-1990 was used as the reference period and 1900-1960 as the validation period. The monthly models account for $50-95 \%$ of the observed variance (correlation coefficients $0.70-0.98$ ), generally more in autumn and winter than in spring and summer. When applied for downscaling modelled values, however, it is crucial that the period for which $\mu$ and $\sigma$ are calculated is comparable in the model and the real world. This period should thus be sufficiently long to avoid large influence from random outliers. Hanssen-Bauer et al. (2000) found-by comparing observations and model output for the periods 1901-30, 1931-60 and 1961-90 - that $30 \mathrm{yr}$ is too short to obtain stable values of $\sigma$. Further, there was no correlation between the observations and model results concerning the variation in $\sigma$ between these periods. This indicates that the variation between the periods mainly is random, and not part of the climate change signal. Thus $\sigma$-values for the 90 yr period 1901-1990 were applied in the final downscaling models. Temperature series were downscaled for the 41 stations shown in Fig. 2a.

For downscaling precipitation, multiple linear regression models were developed using local standardised temperature series and the 6 leading empirical orthogonal functions (EOFs) from the SLP field as predictors:

$\left[R_{X}\right]=a_{0}+a_{1} \cdot \operatorname{EOF} 1+\ldots+a_{6} \cdot \operatorname{EOF} 6+a_{7} \cdot\left[T_{X}\right]$

Here $\left[R_{x}\right]$ is the local precipitation given as a percentage of the 1961-1990 average, $a_{0}-a_{7}$ are regression

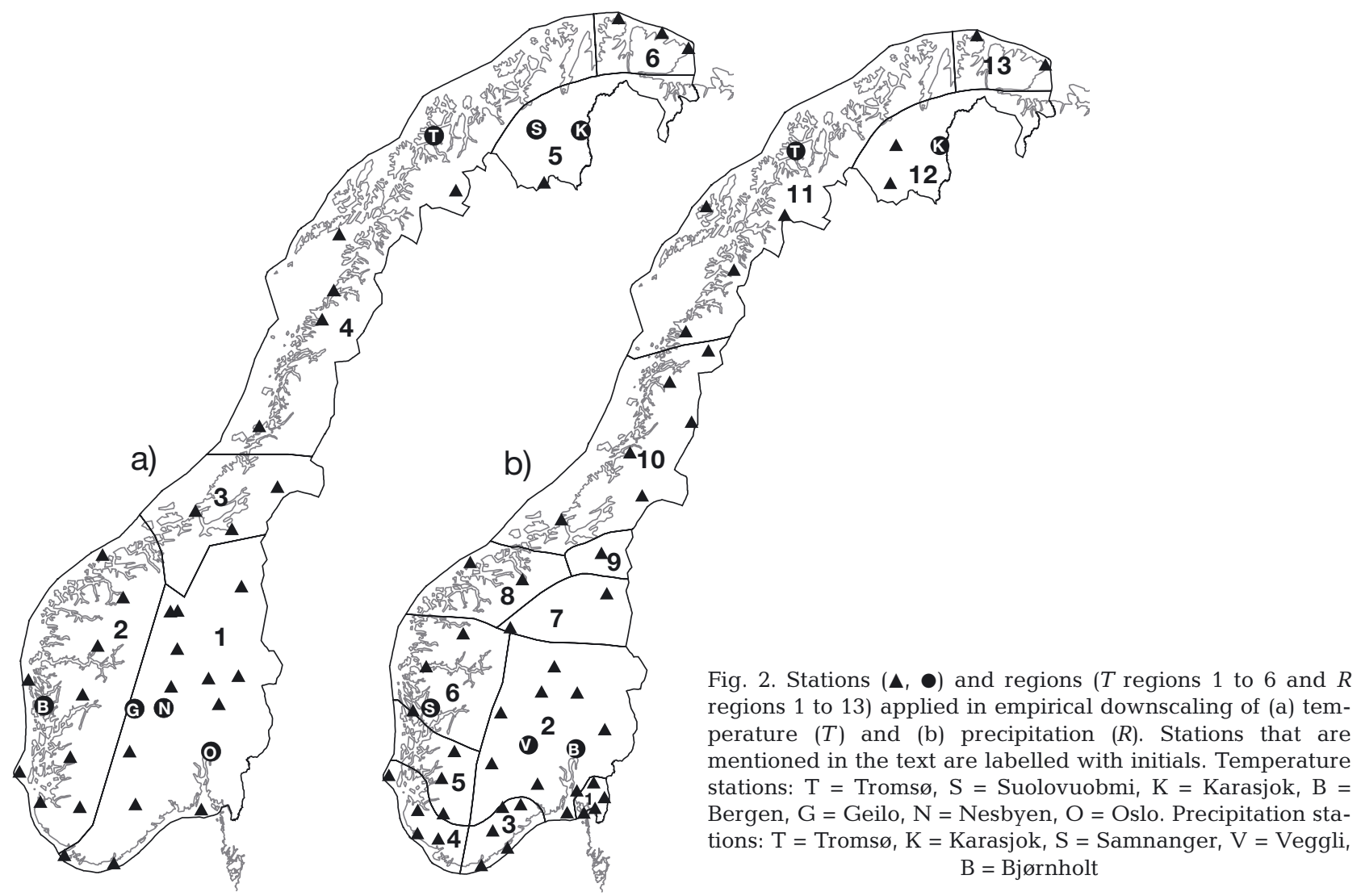


coefficients, and $\left[T_{X}\right]$ is the standardised local temperature. The EOFs are 'common EOFs' based upon observed and GSDIO SLP fields (Benestad 2001). The training period was 1900-1960, while 1961-1998 was used for validation. Models were developed for the 13 precipitation regions (Fig. 2b), which were defined by Hanssen-Bauer et al. (1997). For 55 individual stations, monthly precipitation series (in $\mathrm{mm}$ ) were estimated by multiplying the regional series by the 1961-1990 climatology. At these stations, 30-85\% of the variance in monthly precipitation is accounted for. The model generally scores lower in summer and spring than in autumn and winter. Geographically, the highest scores are achieved along the western coast (e.g. Samnanger; Fig. 2b), while the lowest scores are found in northeastern areas (e.g. Karasjok).

\section{RESULTS}

\subsection{Present climate}

The annual cycles of downscaled temperature and precipitation during 1980-1999 were, for selected sites, compared to observations and to values obtained directly from ECHAM4/OPYC3. The sites were chosen to represent coastal and inland southern and northern Norway. Empirically downscaled values were calculated specifically for the chosen localities. Values from the regional and global models were interpolated from the nearest grid-points, and the temperatures were also adjusted for differences in altitude between model and real topographies $\left(0.65^{\circ} \mathrm{C}\right.$ per $\left.100 \mathrm{~m}\right)$. The global model, as well as both downscaling techniques, gives reasonably realistic annual temperature cycles for most localities (Fig. 3, left-hand panels), though the global model tends to produce too-high temperatures during the autumn at the northernmost stations. Further, both the global and the regional models give toohigh winter temperatures at Nesbyen and Karasjok. During the winter both these sites are exposed to temperature inversions that may last for several days or even weeks. The global model has a resolution too coarse to resolve these ground inversions. The regional model has a better resolution and produces somewhat more realistic winter temperatures at Karasjok, which is situated in relatively smooth terrain. No such improvement is seen at Nesbyen, probably because it is situated in a valley too narrow to be resolved in the regional model topography.

The global model produces, at all sites, an annual precipitation cycle with a minimum in summer and a maximum in autumn or winter (Fig. 3, right-hand panels). Also the precipitation level produced by the global model shows limited spatial variability. Both downscaling techniques produce more realistic annual precipitation cycles, as well as increased spatial variability. At some stations, though, there are substantial differences in level between dynamically downscaled and observed values. Some of these differences result from the smoothed topography in the regional model; that model thus underestimates the precipitation level in the maximum zone some tens of kilometres inland from the west coast (e.g. Samnanger; Fig. 3), while it overestimates the level in the 'rain shadow' east of the watershed (e.g. Veggli). However, due to catch deficiency of the precipitation gauges during solid precipitation and strong winds (Førland \& Hanssen-Bauer 2000), the measured precipitation levels are probably too low during winter at stations where much of the annual precipitation is snow (e.g. Veggli and Karasjok).

The empirical models are tuned by the observed annual cycles of temperature and precipitation, and they may consequently not be evaluated by their ability to reproduce these cycles. To investigate the models' abilities to produce the observed inter-seasonal and inter-annual variability, standard deviations of seasonal and annual averages based on values downscaled from the global model were thus compared to observed values. For temperature (Fig. 4, lefthand panels), there seem to be no systematic differences between the results from the regional model and from the empirical downscaling. In southern Norway, the models do not reproduce the observed winter maximum in standard deviation. This is probably at least partly caused by differences between the real climate and the ECHAM4/OPYC3 climate in 1980-1999. For precipitation (Fig. 4, right-hand panels), the standard deviations based on empirically downscaled values are, for the summer, systematically smaller than those based on the regional model results. This may partly be caused by the fact that the summer models include no predictor that carries information about air humidity. In Karasjok, the precipitation standard deviations based on empirically downscaled values are small in all seasons. This is caused by the fact that this is the area where the empirical precipitation model has the lowest score (cf. Section 2.2).

\subsection{Temperature scenarios}

Annual and seasonal temperature increases from $1980-1999$ to $2030-2049$ in the 6 temperature regions in Fig. 2a were calculated based on the results from dynamical and empirical downscaling (Fig. 5). The results for dynamical downscaling are averages for all grid-points within the respective regions, while the results for empirical downscaling are averages for the 

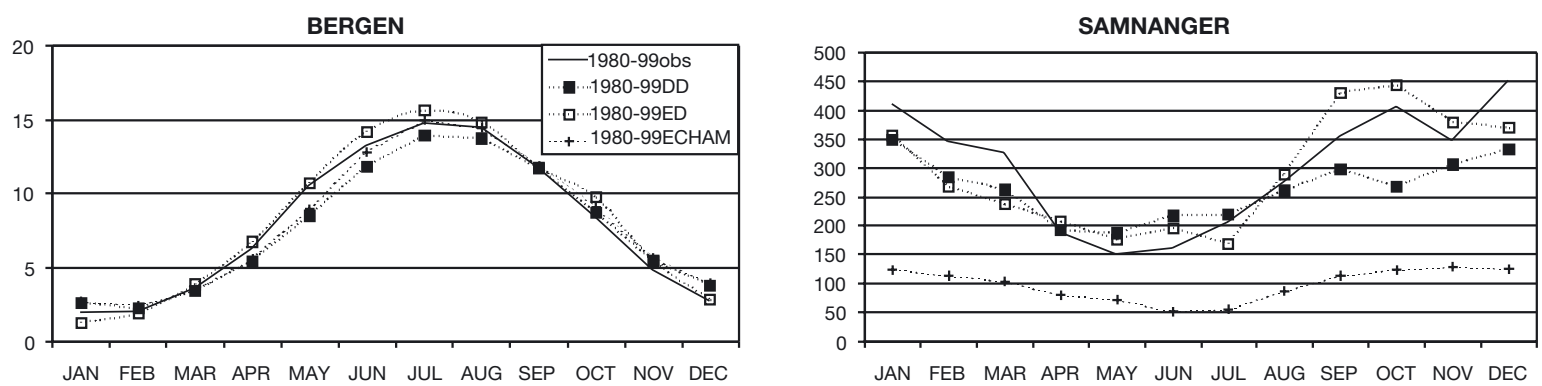

JAN FEB MAR APR MAY JUN JUL AUG SEP OCT NOV DEC
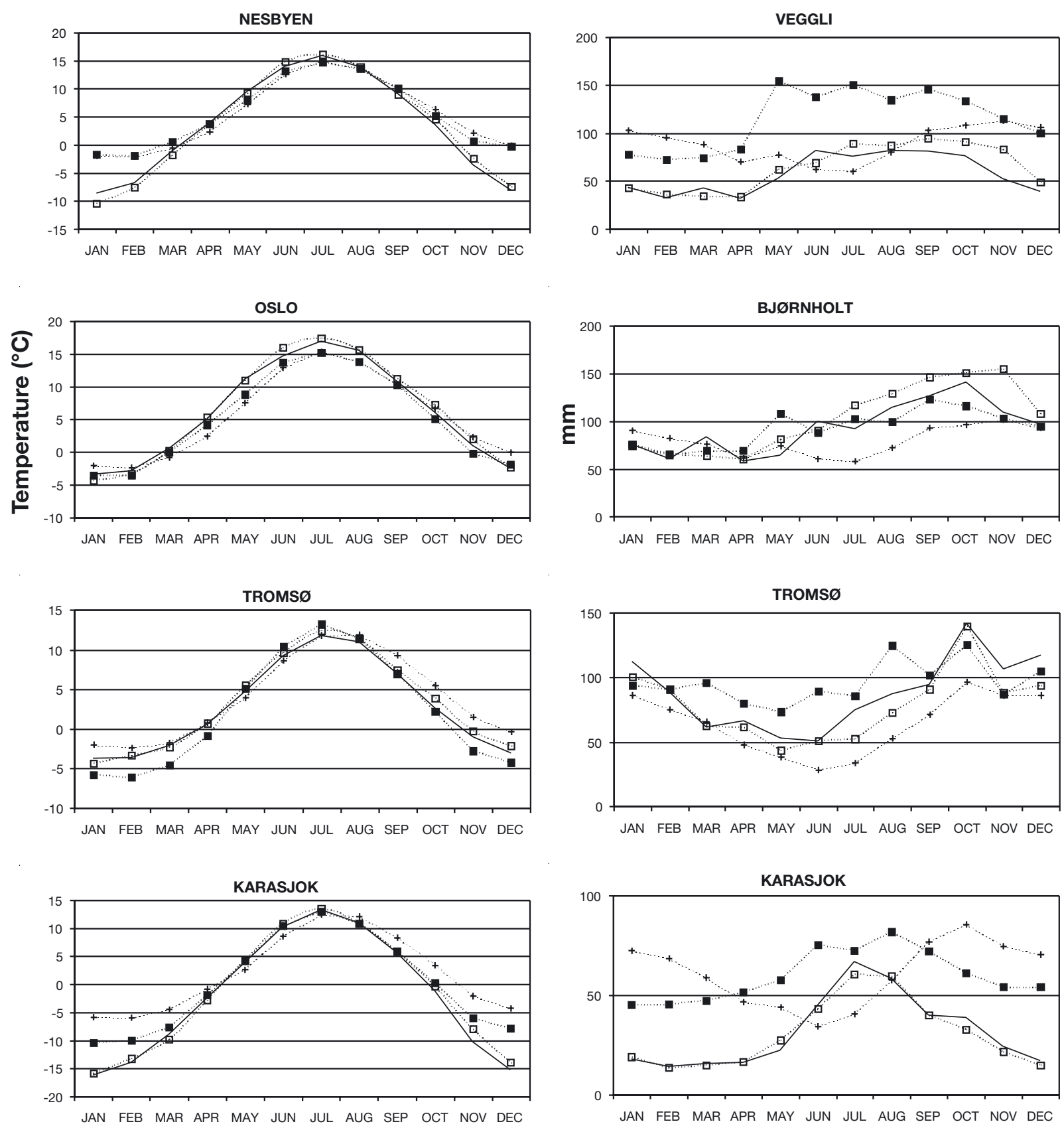

Fig. 3. Seasonal cycle of temperature (left-hand panels) and precipitation (right-hand panels) at selected stations during 1980-1999. Solid line shows observed cycle. Filled and open squares show results from dynamical (DD) and empirical (ED) downscaling, respectively, and the dotted line with crosses shows direct output from the global model 

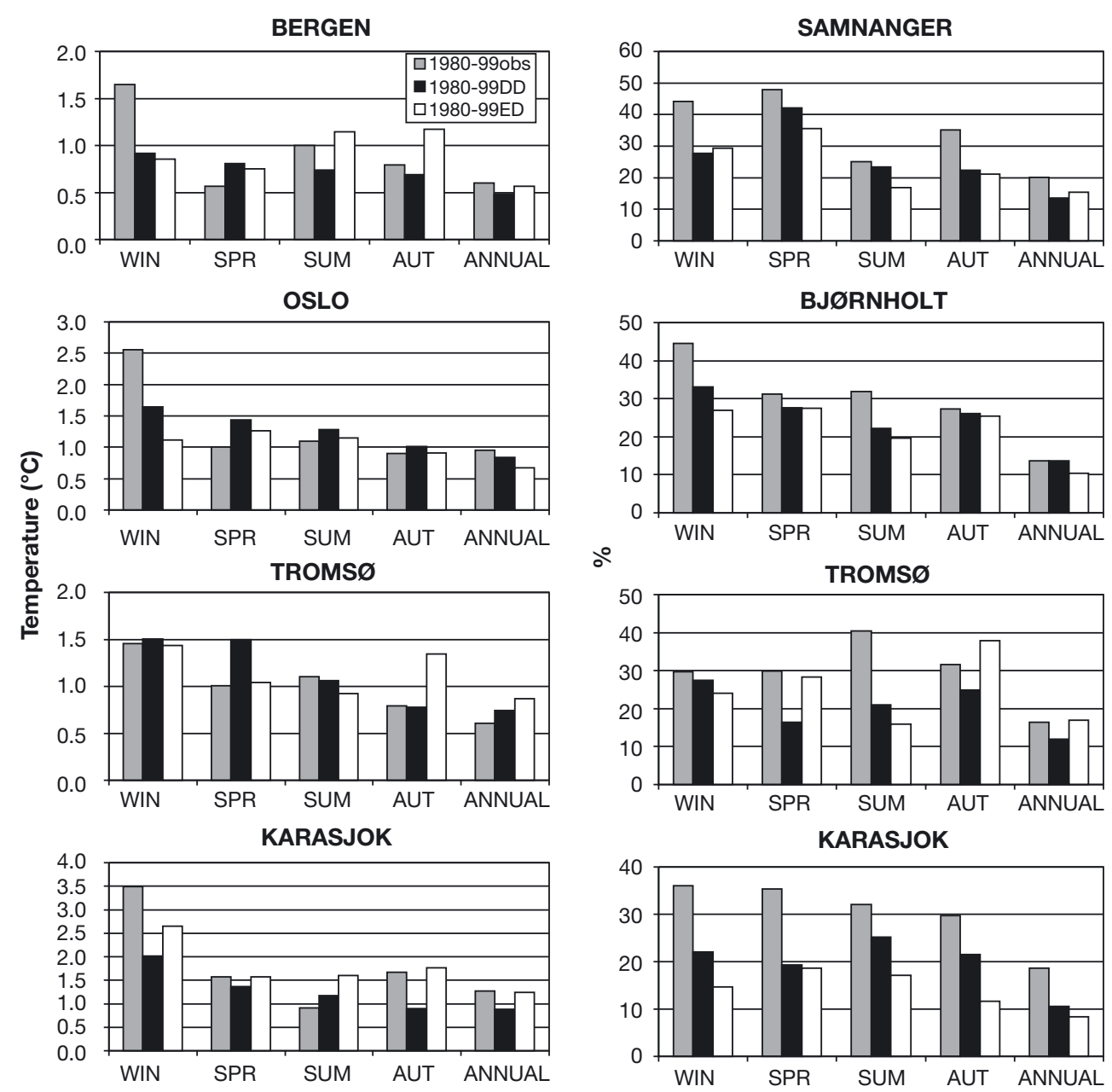

Fig. 4. Observed and modelled standard deviations for temperature (left-hand panels) and precipitation (right-hand panels) at selected stations for 1980-1999. Grey bars show observed values, black and white bars show results from dynamical (DD) and empirical (ED) downscaling, respectively

stations within the regions. The significance of the temperature change was tested at 4 localities (Oslo, Bergen, Tromsø and Karasjok; Fig. 2a). All changes were significant at least at the $5 \%$ level, except the dynamically downscaled summer scenario in Oslo. The 2 approaches show similar geographical patterns for increase in annual mean temperatures: Minimum warming is projected in $T$ regions $1-3$, while the warming rates gradually increase towards the north. The warming rates also tend to be larger inland than along the coast. There are, however, systematic differences: the empirical downscaling tends to give greater warming than dynamical downscaling in all regions and in all seasons except autumn. Maximum differences are found in winter and spring. The significance of the differences was tested at Oslo, Bergen, Tromsø and Karasjok, and none of them were significant at the $5 \%$ level. It was, however, noted that the differences between the dynamically and empirically downscaled scenarios concerning winter and spring warming rates are at a maximum at inversion-exposed inland localities, while they are small along the coast and at mountain stations. This is illustrated in Fig. 6 by comparing the estimated winter warming rates at Nesbyen (valley floor station) and Karasjok (situated in a depression in the landscape) to more freely exposed stations in $T$ regions 1 and 5, respectively.

At selected sites, the results from dynamical and empirical downscaling were also compared to the direct output from ECHAM4/OPYC3. For temperature (Fig. 7, left-hand panels) the warming rates achieved from the global and regional models are, in most cases, similar, though the regional model systematically produces slightly reduced warming rates in winter and spring. The empirical models produce similar winter warming rates to the global model, except for the inversion-exposed sites, where the empirical models produce increased warming rates. 
a) Projected change in annual mean temperature

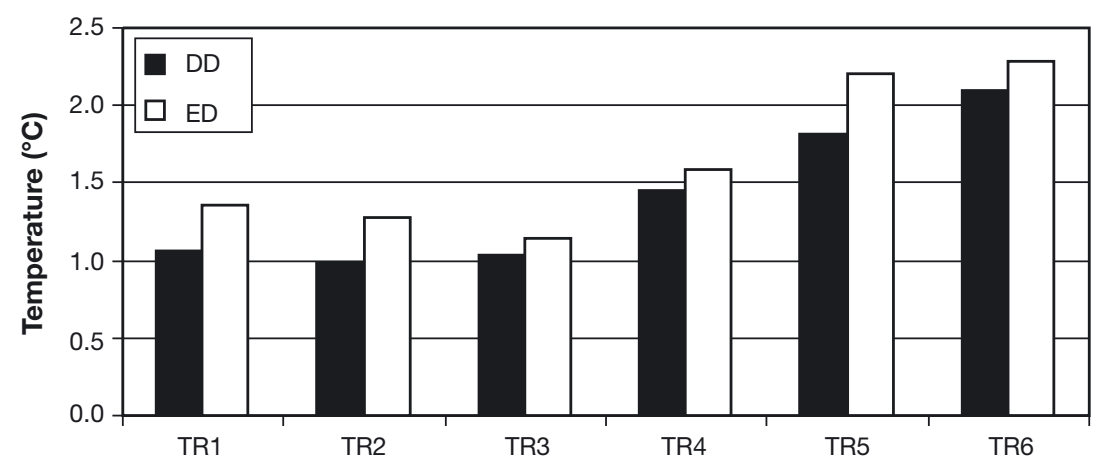

b) Winter

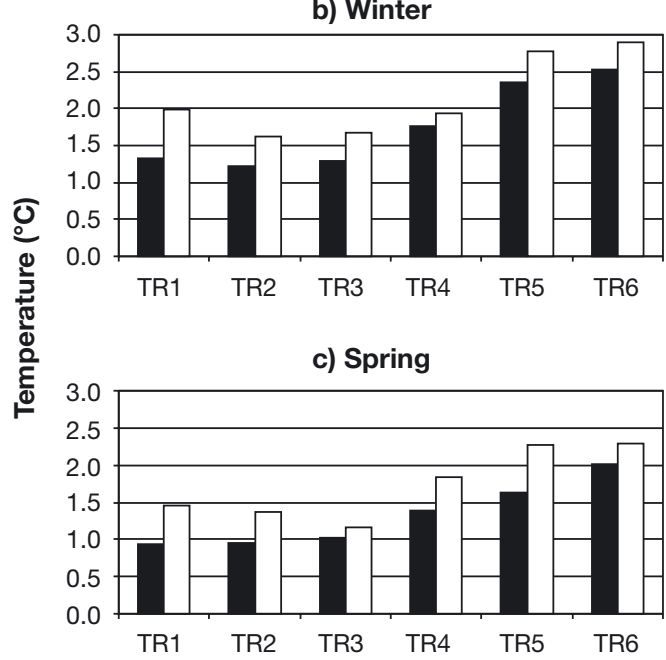

d) Summer

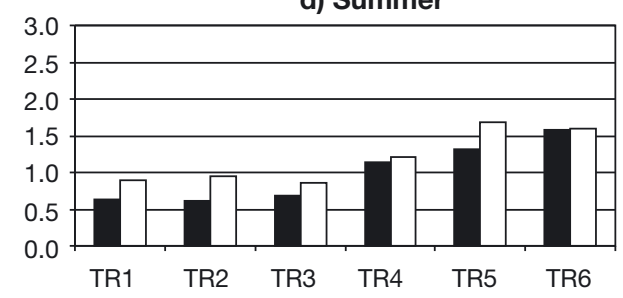

e) Autumn

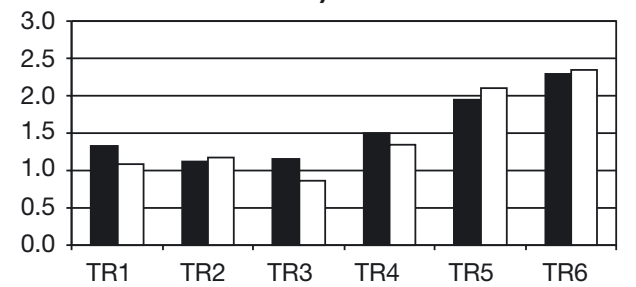

Fig. 5. Projected warming from 1980-1999 to 2030-2049 in the 6 Norwegian temperature regions (TR1 to 6; cf. Fig. 2) according to results from empirical (ED) and dynamical (DD) downscaling of ECHAM4/OPYC3

\subsection{Precipitation scenarios}

Fig. 8 shows precipitation changes from 1980-1999 to 2030-2049 projected by the dynamically and empirically downscaled scenarios for the 13 precipitation regions in Fig. 2b. The significance of the projected changes at 4 localities is given in Table 1 . The 2 approaches show some common geographical patterns: a significant increase in autumn precipitation is projected along the western coast of Norway, while a significant increase in winter precipitation is projected in southern parts of the country. The dynamical downscaling, however, projects a maximum increase in annual as well as autumn precipitation further south along the west coast than the empirical downscaling.

There is also a difference between the downscaling approaches concerning summer precipitation in southwestern Norway (RR5; Fig. 8d) as the dynamically downscaled precipitation scenario shows a significant increase, while the empirical downscaling projects no change. When applying a $t$-test on the differences be- tween the seasonal scenarios at 4 localities (Table 2), this difference in summer precipitation is actually the only significant difference between the seasonal precipitation projections.

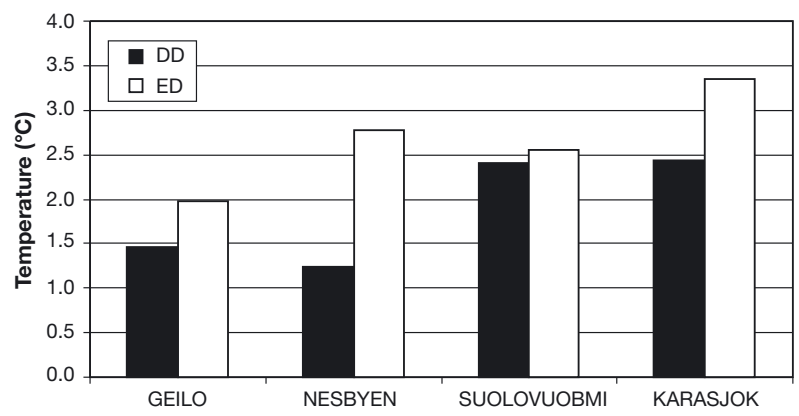

Fig. 6. Projected winter warming from 1980-1999 to 2030-2049 according to results from empirical (ED) and dynamical (DD) downscaling at the more freely exposed station, Geilo, and the valley station, Nesbyen, in $T$ region 1 , and at the similar stations Suolovuobmi and Karasjok in $T$ region 5 
Table 1. Significance (according to a $t$-test) of precipitation changes from 1980-1999 to 2030-2049 for dynamically (DD) and empirically (ED) downscaled scenarios (ns: not significant; s: significant; significance level given in parentheses)

\begin{tabular}{|llccccc|}
\hline Stn & & Winter & Spring & Summer & Autumn & Annual \\
\hline Bjørnholt & DD & $\mathrm{s}(10 \%)$ & $\mathrm{ns}$ & $\mathrm{ns}$ & $\mathrm{ns}$ & $\mathrm{ns}$ \\
& ED & $\mathrm{s}(5 \%)$ & $\mathrm{ns}$ & $\mathrm{ns}$ & $\mathrm{ns}$ & $\mathrm{ns}$ \\
Samnanger & DD & $\mathrm{s}(10 \%)$ & $\mathrm{ns}$ & $\mathrm{s}(1 \%)$ & $\mathrm{s}(1 \%)$ & $\mathrm{s}(1 \%)$ \\
& ED & $\mathrm{s}(5 \%)$ & $\mathrm{ns}$ & $\mathrm{ns}$ & $\mathrm{s}(1 \%)$ & $\mathrm{s}(5 \%)$ \\
Tromsø & DD & $\mathrm{ns}$ & $\mathrm{ns}$ & $\mathrm{ns}$ & $\mathrm{s}(5 \%)$ & $\mathrm{s}(10 \%)$ \\
& ED & $\mathrm{s}(10 \%)$ & $\mathrm{ns}$ & $\mathrm{ns}$ & $\mathrm{s}(1 \%)$ & $\mathrm{s}(1 \%)$ \\
Karasjok & DD & $\mathrm{ns}$ & $\mathrm{ns}$ & $\mathrm{ns}$ & $\mathrm{s}(10 \%)$ & $\mathrm{ns}$ \\
& ED & $\mathrm{ns}$ & $\mathrm{s}(5 \%)$ & $\mathrm{ns}$ & $\mathrm{s}(1 \%)$ & $\mathrm{s}(5 \%)$ \\
\hline
\end{tabular}

than in cold winters. The physical reason is that mild winters have been associated with weather conditions that are unfavourable for ground inversions, i.e. more cyclone activity and consequently more cloudy and windy conditions. In addition, snow cover on the valley floors has probably been less persistent in mild winters, contributing to a positive feedback on the temperature, while snow cover in the Norwegian mountains has been persistent even during mild winters. The empirical downscaling technique applies the assumption

Table 2. Significance (according to a $t$-test) of differences between dynamically and empirically downscaled precipitation scenarios (ns: not significant; s: significant; significance level given in parentheses)

\begin{tabular}{|lccccc|}
\hline Stn & Winter & Spring & Summer & Autumn & Annual \\
\hline Bjørnholt & $\mathrm{ns}$ & $\mathrm{ns}$ & $\mathrm{ns}$ & $\mathrm{ns}$ & $\mathrm{ns}$ \\
Samnanger & $\mathrm{ns}$ & $\mathrm{ns}$ & $\mathrm{s}(1 \%)$ & $\mathrm{ns}$ & $\mathrm{s}(5 \%)$ \\
Tromsø & $\mathrm{ns}$ & $\mathrm{ns}$ & $\mathrm{ns}$ & $\mathrm{ns}$ & $\mathrm{ns}$ \\
Karasjok & $\mathrm{ns}$ & $\mathrm{ns}$ & $\mathrm{ns}$ & $\mathrm{ns}$ & $\mathrm{ns}$ \\
\hline
\end{tabular}

A comparison of the downscaled and original precipitation scenarios at selected sites (Fig 7, left-hand panels) illustrates that both downscaling techniques produce more spatial variability than the global model.

\section{DISCUSSION}

\subsection{Temperature}

Though not statistically significant, the main difference between the empirically and dynamically downscaled temperature scenarios is that empirical downscaling projects considerably greater winter warming in inland valleys than the dynamical downscaling, and also than the global model does. This indicates that the main difference is connected to inversion-exposed areas. The topographical resolution applied in the global model, and even in the regional model, is too coarse to dissolve ground inversions. Thus, if the future winter warming is associated with a weakening of ground inversions, neither the global model nor the dynamical downscaling model would be able to include this part of the warming. The empirical downscaling, on the other hand, projects weaker ground inversions in the future warmer winters, because the ground inversions historically have been weaker in mild winters that future winter warming will follow the patterns of the warm winters of the past, and it may be questioned whether this is reasonable.

Hanssen-Bauer \& Førland (2000) showed that the GSDIO integration, on average, gives a strengthened north-south pressure gradient over Norway during the scenario period. Bjørge et al. (2001) concluded that the results from the dynamical downscaling give an increase, both in average mean $10 \mathrm{~m}$ wind-speed and in precipitation, and that these changes probably are connected to larger cyclonic activity in the area. Knippertz et al. (2000) concluded that the GHG integration (including increasing concentrations of greenhouse gases only) with the ECHAM4/OPYC3 also gives an increase in wind speeds and cyclonic activity in winter. It thus seems reasonable that future winter warming will be accompanied by increased average wind speed and cloud cover, which most likely will lead to weaker and/or less frequent inversions. The expected general reduction of the period with snow-covered ground will also make the conditions less favourable for ground inversions. This may seem to be contradictory to the results from, for example, Giorgi et al. (1997), which show that projected winter warming rates in the Alps increase with elevation, at least up to $2 \mathrm{~km}$. However, the physical explanation of the projected increasing warming rates with elevation is that the winter snow cover in the mountains is reduced in the Alps (Giorgi et al. 1997, Beniston et al. 2003). In Norway, scenarios based upon the ECHAM4/OPYC3 GSDIO integration suggest a reduction in winter snow-cover in the lowlands all over the country. In the high mountains, however, increasing snow amounts are projected, at least up to 2050 (Roald et al. 2002). Snow-cover tends to lower the surface temperatures in several ways: (1) The higher reflectivity reduces solar radiation absorbed at the surface, leading to lower daytime temperatures. (2) Snow acts as a thermal insulator and thus inhibits heat stored in ground from being released to the overlying atmosphere. (3) Melting snow is a sink 
for latent heat, since large amounts of energy are required to melt it. The results from the empirical downscaling are thus probably right in a qualitative sense: the winter warming rates will be higher in valleys and at other inversion-exposed locations, where snow-cover is reduced, than in the mountains, where the snow storage is increased, and along the coast, where snow-cover will remain sporadic. It is still likely that the empirical downscaling technique exaggerates the effect of reduced inversions, as the future warming may be less related to increased cyclone activity than the mild winters of the past.
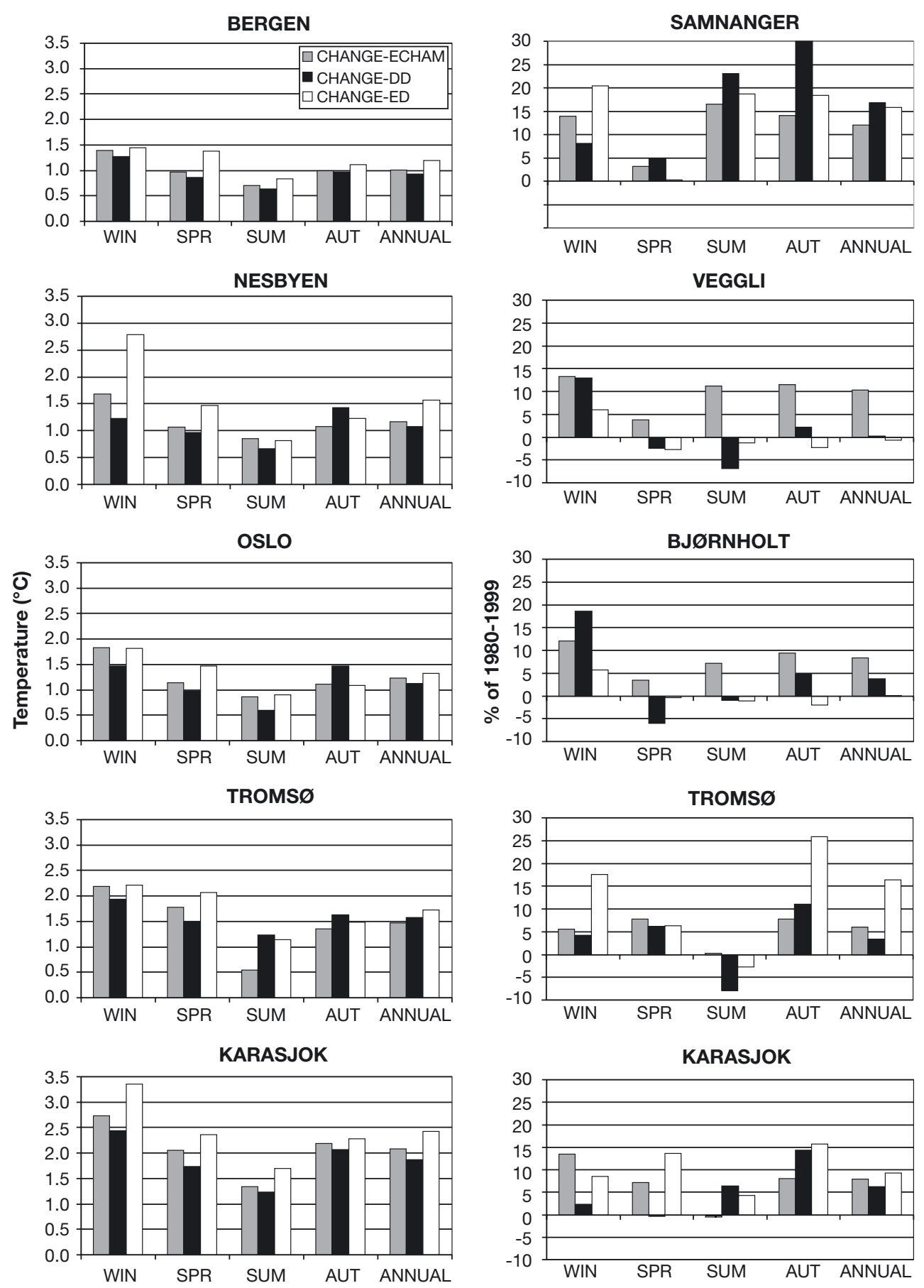

Fig. 7. Projected annual and seasonal change in temperature (left-hand panels) and precipitation (right-hand panels) at selected stations from 1980-1999 to 2030-2049. Grey bars show direct output from the global model, black and white bars show results from dynamical (DD) and empirical (ED) downscaling, respectively 
a) Projected change in annual precipitation
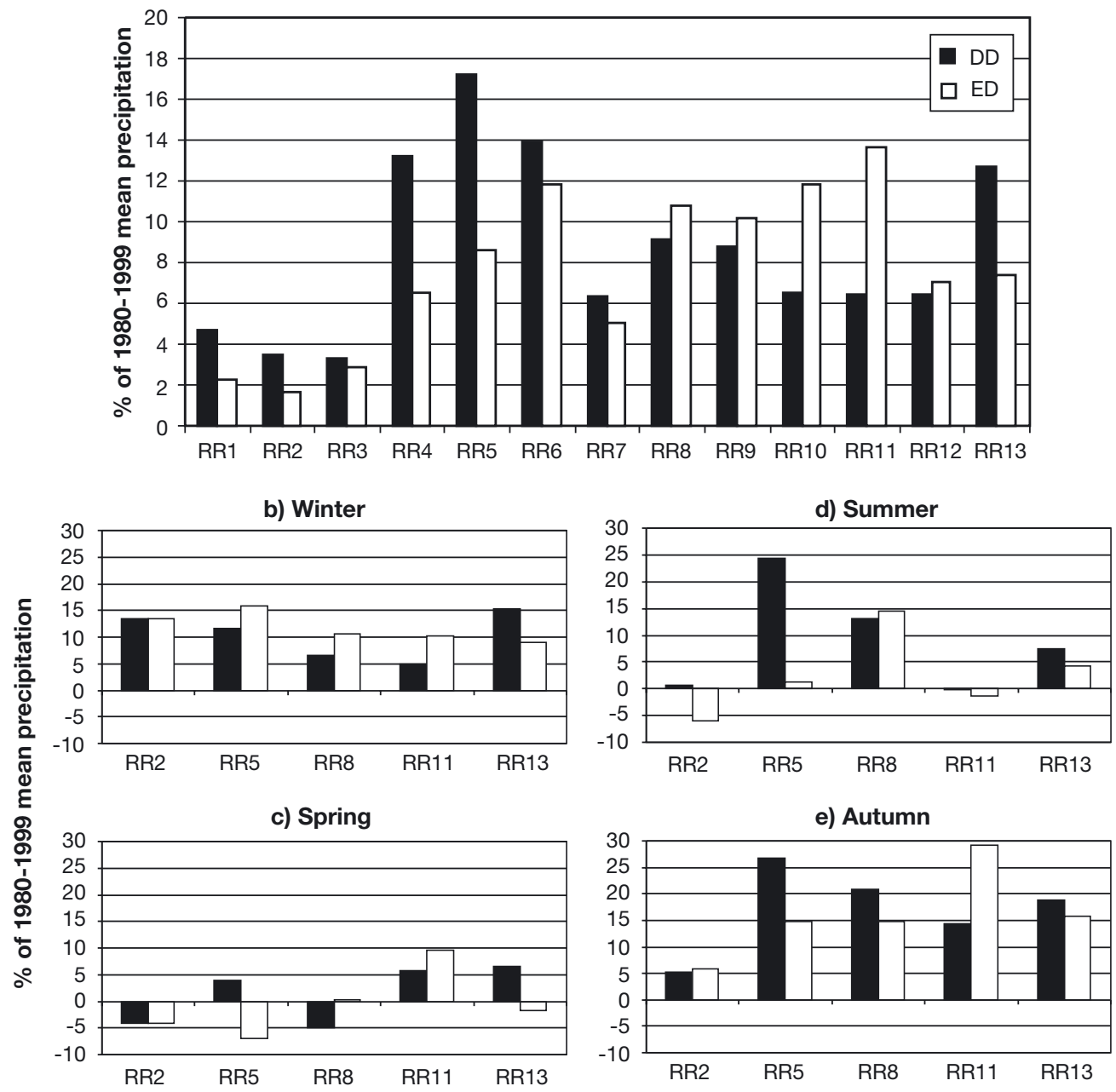

Fig. 8. Projected precipitation changes from 1980-1999 to 2030-2049 in the 13 Norwegian precipitation regions (RR1 to 13; cf. Fig. 2) according to results from empirical (ED) and dynamical (DD) downscaling of ECHAM4/OPYC3

\subsection{Precipitation}

The direct results from the global model clearly show that the spatial resolution is too coarse to capture local differences in precipitation changes caused by effects of topography. For instance, in autumn, the global model projects, on average, an increased north-south pressure gradient, and thus an increased on-shore wind component along the Norwegian west coast. This is consistent with a substantial increase in the precipitation in western regions (e.g. Samnanger), but not east of the mountains (e.g. Veggli). Thus downscaling is crucial to produce reasonable precipitation scenarios at a local scale.

The only statistically significant difference between the results of the 2 downscaling approaches was found during summer, when the dynamical downscaling projects increased precipitation in southwestern Norway, while empirical downscaling projects no significant change. The present empirical downscaling method has a clear weakness concerning summer precipitation, as only changes connected to changes in the SLP field are modelled in this season. Eventual changes connected to, for example, the expected intensification of the hydrological cycle are not included. The empirical model may be improved by the inclusion of air humidity as a predictor.

Hellström et al. (2001) compared empirically and dynamically downscaled precipitation scenarios for Sweden based upon HadCM2 (Johns et al. 1997) and ECHAM4. They included humidity at $850 \mathrm{hPa}$ as a predictor in their empirical downscaling model. Still, the largest spread in the downscaling results occurred in summer, maybe because the empirical models have limited skills concerning convective precipitation (Kidson \& Thompson 1998). As dynamical climate 
models may also have problems with modelling summer precipitation (Wilby \& Wigley 2000), we thus suggest that the dynamically downscaled results are most realistic concerning summer precipitation.

Though not significant, there were also differences between the downscaled precipitation scenarios concerning the location of the area of maximum precipitation increase. Both scenarios showed a maximum increase along the western coast, but the empirically downscaled scenario showed a maximum increase further north than the dynamically downscaled scenario. The reason for this difference is unclear, but preliminary results from the RCM suggest that the exact position of maximum precipitation change is sensitive to the choice of integration area. A smaller area than that presently applied produced a maximum precipitation increase more in agreement with the results from the empirical downscaling. The present analysis gives no clue as to which of these results is the most plausible.

\section{SUMMARY AND CONCLUSIONS}

Analysis of differences between results from dynamically and empirically downscaled climate scenarios based on the same global model run may reveal weaknesses of the respective methods. In the present investigation, empirical downscaling tends to give higher warming rates than dynamical downscaling, especially during winter at sites that are exposed to temperature inversions. Though the differences are not statistically significant at the $5 \%$ level, it is discussed whether the geographical signature of the empirically downscaled warming rates, which implies a reduction in the average strength of ground inversions during winter, is reasonable. The dynamical downscaling model does not resolve ground inversions properly, and it is thus unable to either support or contradict this feature. It is concluded that a reduction in frequency and/or average strength of winter inversions is consistent with the projected increase in wind speed and reduced winter snow-cover in the lowlands. The results from the empirical downscaling are thus probably qualitatively right, although they may exaggerate this feature.

For precipitation, a statistically significant difference between dynamically and empirically downscaled scenarios was found in summer in southwest Norway. The results from the dynamical downscaling are probably the most reliable, as the present empirical downscaling models for the summer months can only reproduce changes caused by variations in atmospheric circulation. There are also some differences between dynamically and empirically downscaled scenarios concerning the exact areas of maximum precipitation increase. These are not statistically significant, though, and they may partly depend on choice of downscaling domain.

The empirical and dynamical downscaling results agree on central points. The projected temperature increase is at a maximum in winter and at a minimum in summer. The warming rate increases from south to north and from the coast to inland. Both downscaling techniques give a statistically significant precipitation increase in winter precipitation in southern Norway and in autumn precipitation in western and northern regions. Agreement between the downscaling models is no guarantee for the realism of the modelled climate change, but it adds credibility to the results, given that the large-scale scenario is realistic. Still, both techniques have their shortcomings. Empirical models depend critically on the choice of predictors. Most regional models, on the other hand, still have a resolution too coarse to produce scenarios on the spatial scales that are requested for many climate change impact studies. We thus find it useful to continue developing and evaluating both techniques. The empirical models will be improved by including air humidity as a predictor for precipitation, and by improving the time resolution, while the regional models will be improved by increasing the spatial resolution. In addition, in order to meet the increasing demand for climate scenarios for application in impact studies, we are developing methods for empirical/statistical refinement of the output from regional models.

Acknowledgements. The present paper is a product of the project 'Regional climate development under global warming' (RegClim), which is supported by the Norwegian Research Council (NRC Contracts No. 120656/720). The authors are indebted to 3 anonymous reviewers for their constructive suggestions.

\section{LITERATURE CITED}

Allen MR, Stott PA, Mitchell JFB, Schnur R, Delworth TL (2000) Quantifying the uncertainty in forecasts of anthropogenic climate changes. Nature 407:617-620

Benestad R (2001) A comparison between two empirical downscaling strategies. Int J Climatol 21:1645-1668

Beniston M, Keller F, Goyette S (2003) Snow pack in the Swiss Alps under changing climatic conditions: an empirical approach for climate impacts studies. Theor Appl Climatol 74:19-31

Bjørge D, Haugen JE, Nordeng TE (2000) Future climate in Norway. DNMI Research Report 103, Norwegian Meteorological Institute, Oslo

Christensen JH, Christensen OB, Lopez P, van Meijgaard E, Botzet M (1996) The HIRHAM4 regional atmospheric climate model. DMI Scientific Report 96-4, Danish Meteorological Institute, Copenhagen

Christensen OB, Christensen JH, Machenhauer B, Botzet M (1998) Very high-resolution regional climate simulations over Scandinavia - present climate. J Clim 11:3204-3229

DKRZ (Deutsches Klimarechenzentrum) (1992) The ECHAM- 
3 atmospheric general circulation model. DKRZ Technical Report 6, Hamburg

Førland EJ, Hanssen-Bauer I (2000) Increased precipitation in the Norwegian Arctic: true or false? Clim Change 46: 485-509

Giorgi F, Hurrell JW, Marinucci MR, Beniston M (1997) Elevation signal in surface climate change: a model study. J Clim 10:288-296

Giorgi F, Hewitson B, Christensen JH, Hulme M and 5 others (2001) Regional climate information-evaluation and projections. In: Houghton JT, Ding Y, Griggs DJ, Noguer M, van der Linden PJ, Dai X, Maskell K, Johnson CA (eds) Climate change 2001: the scientific basis. Contribution of Working Group I to the Third Assessment Report of the Intergovernmental Panel on Climate Change. Cambridge University Press, Cambridge, p 583-638

Hanssen-Bauer I, Førland EJ (1994) Homogenizing long Norwegian precipitation series. J Clim 7:1001-1013

Hanssen-Bauer I, Førland EJ (2000) Temperature and precipitation variations in Norway 1900-1994 and their links to atmospheric circulation. Int J Climatol 20:1693-1708

Hanssen-Bauer I, Førland EJ (2001) Verification and analysis of a climate simulation of temperature and pressure fields over Norway and Svalbard. Clim Res 16:225-235

Hanssen-Bauer I, Førland EJ, Tveito OE, Nordli PØ (1997) Estimating regional precipitation trends-comparisons of two methods. Nordic Hydrol 28:21-36

Hanssen-Bauer I, Tveito OE, Førland EJ (2000) Temperature scenarios for Norway. Empirical downscaling from ECHAM4/OPYC3. Klima Report 24/00, Norwegian Meteorological Institute, Oslo

Hanssen-Bauer I, Tveito OE, Førland EJ (2001) Precipitation scenarios for Norway. Empirical downscaling from ECHAM4/OPYC3. Klima Report 10/01, Norwegian Meteorological Institute, Oslo

Hellström C, Chen D, Achberger C, Räisänen J (2001) Comparison of climate change scenarios for Sweden based on statistical and dynamical downscaling of monthly precipitation. Clim Res 19:45-55

Johns TC, Carnell RE, Crossley JF, Gregory JM, Mitchell JBF, Senior CA, Tett SBF, Wood RA (1997) The second Hadley Centre coupled ocean-atmosphere GCM: model description, spinup and validation. Clim Dyn 13:103-134

Jones PD (1987) The early twentieth century Arctic highfact or fiction? Clim Dyn 1:63-75

Jones PD, Raper SCB, Bradley RS, Diaz HF, Kelly PM, Wigley TML (1998) Northern hemisphere surface air temperature variations 1851-1994. J Climatol Appl Meteorol 25: 161-179

Källén E (ed) (1996) HIRLAM documentation manual, System 2.5. Swedish Meteorological and Hydrological Institute, Norrköping

Editorial responsibility: Hans von Storch, Geesthacht, Germany
Kidson JW, Thompson CS (1998) comparison of statistical and model-based downscaling techniques for estimating local climate variations. J Clim 11:735-753

Knippertz P, Ulbrich U, Speth P (2000) Changing cyclones and surface wind speeds over the North Atlantic and Europe in a transient GHG experiment. Clim Res 15: 109-122

Machenhauer B, Windelband M, Botzet M, Christensen $\mathrm{JH}_{\text {, }}$ Déqué M, Jones RG, Ruti PM, Visconti G (1998) Validation and analysis of regional present-day climate and climate change simulations over Europe. MPI Rep 275, MaxPlanck-Institüt für Meteorologie, Hamburg

Murphy J (1999) An evaluation of statistical and dynamical techniques for downscaling local climate. J Clim 12: $2256-2284$

Murphy J (2000) Predictions of climate change over Europe using statistical and dynamical downscaling techniques. Int J Climatol 20:489-501

Nordli P (1997) Homogeneity testing of Norwegian temperature series II. Klima Report 29/97, Norwegian Meteorological Institute, Oslo

Oberhuber JM (1993) Simulation of the Atlantic circulation with a coupled sea ice-mixed layer-isopycnal general circulation model. Part I: Model description. J Phys Oceanogr 22:808-829

Roald LA, Beldring S, Væringstad T, Engeset R, Skaugen TE, Førland EJ (2002) Scenarios of annual and seasonal runoff for Norway based on climate scenarios for 2030-2049. Klima Report 19/02, Norwegian Meteorological Institute, Oslo

Robock A (1980) The seasonal cycle of snow cover, sea-ice and surface albedo. Mon Weather Rev 108:267-285

Roeckner E, Arpe K, Bengtsson L, Christof M and 6 others (1996) The atmospheric general circulation model ECHAM4: model description and simulation of presentday climate. Report No 218, Max-Planck-Institut für Meteorologie, Hamburg

Roeckner E, Bengtsson L, Feichter J, Lelieveld J, Rodhe H (1999) Transient climate change simulations with a coupled atmosphere-ocean GCM including the tropospheric sulphur cycle. J Clim 12:3004-3032

Singleton F, Spackman EA (1984) Climatological network design. Meteorol Mag 113:77-89

Tiedke M (1989) A comprehensive mass flux scheme for cumulus parameterization in large-scale models. Mon Weather Rev 117:1779-1800

Wilby RL, Wigley TML (2000) Precipitation predictors for downscaling: observed and general circulation model relationships. Int J Climatol 20:641-661

Yarnal B, Comrie AC, Frakes B, Brown DP (2001) Review. Developments and prospects in synoptic climatology. Int J Climatol 21:1923-1950

Submitted: November 12, 2002; Accepted: June 29, 2003 Proofs received from author(s): September 23, 2003 